\title{
The Factor That Affects the City's Readiness to Adopt Electric Vehicles: A Conceptual Paper
}

\author{
Ismail Nooraini $^{1, *}$ Nor Hasni Osman ${ }^{1}$, Siti Norhasmaedayu Mohd Zamani ${ }^{1}$ \\ ${ }^{I}$ School of Technology Management \& Logistics (STML) Universiti Utara Malaysia Kedah, Malaysia \\ *Corresponding author. Email: mail.noraini@gmail.com
}

\begin{abstract}
Transportation is one of the highly demanded industries as a benefit to the owner at this time as rapid access to any geographical location in the world. However, some drawbacks arise when this sector contributes to worldwide environmental pollution. This paper compiled and analyzed the previous literature, which addresses the variables necessary to evaluate the readiness to adopt electric vehicles to become a low-carbon city.
\end{abstract}

Keywords - Electric Vehicle, the evolution of electric vehicle, city readiness, transportation

(HEV), and extended-range electric vehicles (E-REVs) are four types of EVs introduced to the market [20].

\section{INTRODUCTION}

The focus of global warming is often on energy and industrial activity. Human activities cause the most significant global warming, contributing to increased atmospheric greenhouse gas (GHG) emissions over the last 150 years [11]. Low-carbon vehicles in the transportation sector may potentially bridge the gap between the importance of reducing climate change and transport ownership.

Today, environmental awareness has been a critical issue worldwide, motivating the urgency to call on EVs to re-enter the industry. This awareness is mainly due to the high impact of global climate change on fossil fuel combustion emissions [16]. Because they are concerned about oil depletion, supply security, and climate change, many countries are increasingly looking at traditional road transport technology alternatives. Moreover, the world has begun to develop strategies to introduce EVs as an option to reduce dependence, such as on fossil fuels, increase oil prices, and reduce $\mathrm{CO} 2$ emissions.

The literature perceives that EVs have contributed up to twenty percent of the global warming potential decrease in Europe [18]. Also, by having lower noise, higher energy efficiency, and reducing $\mathrm{CO} 2$ [22], EVs have been claimed to benefit conventional gasoline vehicles [22]. Battery electric vehicles (BEV), plug-in hybrid electric vehicles (PHEV), hybrid electric vehicles
Presently, as awareness of environmental issues has increased worldwide, the use of EVs has spread widely. Many countries are very interested in the idea of having a low-pollution city, despite the challenges of encouraging individuals to use and own EVs. Therefore, it is crucial to understand the factors that influence the nation's readiness to adopt electric vehicles. This paper's primary motivation hoped to help the automotive industry and the government have additional capacity to understand the variables necessary to successfully adopt EVs on a global scale previous research [6].

\section{LITERATURE REVIEW}

It is possible to classify a literature review as a systemic way of reporting the current state of knowledge in a specific area [25]. To ensure the literature review is meaningful, it is necessary to carry out a well-defined protocol by allocating existing data, selecting the papers using specific criteria, evaluating, analyzing, synthesizing, and reporting the results. The literature review aims to achieve precise and understandable knowledge of the subject [7], [33], [1].

Besides, to find the gap, variables, and solutions to research questions and goals, researchers used a systematic review of the existing literature. The systematic literature review used to identify this research, selecting previous research on factors influencing the city's readiness to adopt electric 
vehicles. In the platforms for this study, keywords such as " electric vehicles "," technology readiness '," adoption factors'," barriers" and" challenges" were used using multiple electronic literature databases provided by several platforms, such as SCOPUS, PROQUEST, ScienceDirect, IEEE Xplore, PUBMED, and EMERALD. In terms of EVs criteria and factors, the articles were found and sorted. Using the English language, peer-reviewed, and focused on factors influencing the readiness and adoption of EVs, the papers selected are not more than ten years ago. Based on systematic sorting and categorizing, the next section presents a review of the previous relevant literature.

\section{Evolution of Electric vehicles}

At the beginning of the entire car industry itself, the evolution of EVs was already established. Some other breakthroughs in electrically powered vehicle technology were made by engineers and scientists starting in the 1830s. In 1832, the first functioning electric vehicle ware introduced by British inventor Robert Anderson. There have been several innovations from countries such as the United States, the Netherlands, and Hungary [23].

The EVs industry had become famous when the advantage of easy operation, especially among women, was significant in electrically powered cars. It was the perfect vehicle for short-distance city traffic when the benefits of non-pollution contributed to the industry compared to gasoline cars [27], [8]. These facts affected the market, and electric cars entered the new century, showing that EVs were sold ten times more than gasoline cars. The EVs were dominated by the dealer showroom and the road and were a trend until the mid1910s. At that time, Studebaker and Oldsmobile were among the famous car manufacturers [15].

EVs were the most extensive product development at the beginning of 1912, when 34,000 cars were registered. The early popularity of EVs was since they were quieter and less dangerous and more comfortable to drive than combustion engine-driven cars [21]. However, the hand crank's major disadvantages appear, and the petrol-powered car industry's sales suddenly increased. In the $1920 \mathrm{~s}$, the United States faced a situation in which the market lowered gasoline prices and began to increase the network of gas stations across the country.

Electricity remained inaccessible in most rural areas for the time being. However, the combustion engine cars finally broke off electric vehicles in 1935 and dropped from the market for a long time [23]. Over 30 years, combustion engines' dominance has led to a lack of electric motor technology and overall development. Electricity was left in the dark to concentrate on combustion technology's advancement at lower oil prices [27]. Due to the awareness of pollution and disasters, it is the United States' responsibility to meet certain air quality objectives. As a result, the Clean Air Act was introduced in 1970.

U.S. oil prices peaked in 1973 with the supply of Saudi Arabia. At the same time, global oil prices began to rise, and the supply of oil resources was limited. Because of this, they tried to find domestic oil resources instead of relying on foreign oil resources. After three years, the government adopted the 1976 Act on the Research, Development, and Demonstration of Electrical and Hybrid Vehicles to explore alternative fuel options [23]. France also took part in the RD\&D electric vehicle in 1976, the so-called 'PREDIT' [8], due to the same problems.

Two companies are now leading the electric car market, Sebring-Vanguard and Alcar Corporation. Sebring-Vanguard successfully produced more than 2,000 "CitiCars" in the 1970s. Alcar Corporation produced the "CityCar," the most sold electric car in the U.S. until Tesla Roadster launched in 2006. As an example from the European car scene, the German car manufacturer BMW tried their luck at the Munich Olympic Games in 1972, when they introduced their 1602 E model. This car powered by a 42-horsepower full-electric engine with a single-charge range of 37 miles. However, during the Olympic Games, the electric motor vehicle never achieved mass production [33].

Worldwide interest in the electric car is very welcome as time has changed. For this reason, General Motor has launched the first EV1 model. It's become America's best-selling electric vehicle. Because it's a pioneer vehicle production in 1996, the market strength sold has gained public excitement and interest, selling 1117 units at the time. However, General Motors could not turn its profit from EVs in 2001 and made it disappear again [4].

In 1997, when Toyota introduced its Prius, Japan reacted to the EVs market. Prius sales became the best selling worldwide in 2000. A new start-up company has emerged in Silicon Valley to support industries. Their first car, a full-electric Tesla Roadster 2006, is called Tesla Motors. Due to their limited resources, the car was produced based on the existing car-maker, Lotus Elise. The American Energy Department provided a \$465 million loan to Tesla Motors due to the problem. As a result, their giga-factory building was successfully built by Tesla Motors, making Tesla California 's largest automaker. The company's financial situation changed dramatically, allowing the company in 2013 to repay its debts [23]. Although the technology moves very quickly, it can closely link EVs technology with users and nations' awareness, thus contributing to high demand for the industry [27] is very welcome. 
Table 1.1: Summary of EVs evolution

\begin{tabular}{|c|c|}
\hline $\begin{array}{l}\text { Rec } \\
\text { ent }\end{array}$ & $\begin{array}{l}\text { EVs are one of the chosen vehicles } \\
\text { in the world. }\end{array}$ \\
\hline 200 & $\begin{array}{l}\text { Tesla Motors introduced fully EVs } \\
\text { model Tesla Roadster. }\end{array}$ \\
\hline 199 & $\begin{array}{l}\text { Japan came out to respond to the } \\
\text { semi EVs (Toyota Prius) }\end{array}$ \\
\hline 197 & $\begin{array}{l}\text { "PREDIT" program introduced to } \\
\text { call back EVs }\end{array}$ \\
\hline 197 & $\begin{array}{l}\text { Sebring-Vanguard } \\
\text { produced "CitiCars." }\end{array}$ \\
\hline 193 & $\begin{array}{l}\text { The EVs were beaten and } \\
\text { disappeared }\end{array}$ \\
\hline 191 & EVs start production development \\
\hline 183 & $\begin{array}{l}\text { First EVs introduced by Robert } \\
\text { Anderson }\end{array}$ \\
\hline $0^{183}$ & $\begin{array}{l}\text { Engineers and scientists came up the } \\
\text { research of EVs }\end{array}$ \\
\hline
\end{tabular}

\section{Revolution of readiness}

Readiness Digital technology gradually incorporated into our everyday lives and how goods and services were obtained and consumed. Revolution to readiness refers to the organization's level of preparation to develop innovative ideas and ensure it realizes. The revolution or the innovation readiness comprises two main parts; the organization's innovation propensity and the context of implementation. Innovation propensity concerns how well the organization incorporated innovation into its goals, vision, mission, and business model and whether innovation was considered a strategic focus [10].

The implementation context refers to how the company carries out different types of innovations, i.e. whether progressive innovations ware implemented in line with disruptive innovations. A flexible implementation of innovation is essential as different innovation types require radically different processes and structural management than its traditional business [17], [25]. A company must have a high propensity to innovation and a context of implementation that supports different types of innovations to have a high standard of innovation readiness.

In this research, innovation readiness can be defined as the city's level of preparation for electric vehicle adoption. Based on this study, the readiness variables for adopting new technology can be divided into five main categories: technology, infrastructure, advertising and promotion, government support, and consumer acceptance.

\section{Technology readiness}

For decades, technological advancement has been standard for human development. In their daily lives, EVs and their technologies are part of the transportation industry that serves people. Also, for the success of Evs, technology readiness is considered essential. As technology is rapidly changing, it can not to overlooked. Highly advanced technology is needed for the successful implementation of Evs. According to [28], Evs has increased interest in reducing road transport pollution. Although most of this focus is on passenger vehicles, the potential for Evs technology products has been somewhat less studied. Otherwise, in areas with clean electricity generation sources, Evs can significantly reduce greenhouse gas emissions [29]. This study's technology readiness factor includes the needs of specialist personnel and electric vehicle maintenance centers.

\section{Infrastructure readiness}

The availability of infrastructure is considered essential for the success of EVs' adoption [1]. The improvement of road infrastructure for vehicle operations was continually essential. Based on IDTechEx 's research on Evs, more than 100 million Ev's plugins will be available on the road by 2030 , including passenger vehicles, buses, trucks, and freight forwarders. Infrastructure shows that it is crucial to consider the charging infrastructure. In the coming decade, electric passenger vehicles will be expected to overgrow, significantly increasing the demand for charging infrastructure [36].

Furthermore, [27] consider that charging infrastructure may be essential to attract groups other than the traditional early adopters of PEVs. Public charging infrastructure should be open to the public and located on publicly owned land. [12] has analyzed the three types of public recharge infrastructure used in light cars: (1) recharging (near home) as a substitute for privately charged vehicles; (2) charging opportunities in points of interest (POI charging), e.g., in groceries; and (3) fast charging in the long-distance (D.C. high charging) journey corridors of high charge. Thus, for this study, infrastructure factors, also looking for charging port and parking space provided.

\section{Advertising and Promotion}

The apparent advantages in terms of government investment in advertising and promotion are significant. This promotion must be a highlight to explore innovative business models related to vehicle use and charging infrastructure operation. The advertising and promotion of directional purchase in the private sector should promote. Successful business models should 
promote a service guarantee mechanism to create a goods environment for EVs operation. Besides, EVs publicity and promotion activities should extensively develop to strengthen consumer awareness [36]. For this study, adverting and promotion include the launch introduction of EVs by the government and private sectors to the cities' people. There are apparent advantages to public investment in advertising and promotion. This promotion must be a highlight in the exploration of innovative business models such as for vehicle use and infrastructure charging. Publicity and promotion of directional purchases should also be promoted from the private sector to expand the scope of EV adoption. For this study, advertising and promotion are looking at the promotion of offline and online methods.

\section{Government support}

To help the future of Evs, policymakers, scholars, and professionals need to collect and make essential decisions [2]. Besides, in order to adjust the current technology policies, knowledge from the policymaker is required. The changes are necessary by solving regulatory problems, especially before the widespread introduction of high or conditional Evs on the road. [3] indicate that governments are currently relying on conventional vehicles' laws regarding policy and regulation, while new laws are in process, and there are uncertainties in Evs' technology. Adaption to the new traffic policies also should be implemented [25], [1]. Other than policy, subsidies, tax cuts, and financial assistance should also cover for this factor.

\section{Consumer acceptance}

Along with [1] study, greater acceptance of EVs can be aimed at addressing highly mobile individuals living in urban areas. [6] point out that two significant factors, internal and external, affect user acceptance. Some of the factors discussed by [8] and [5] recognize that EVs' adoption is affected by driving range, cost of ownership of vehicles, and charging time. They agreed that significant impediments to EV adoption are the internal factor related to EVs' high purchase price, battery costs, limited driving range, and possibly long charging time requirements [6]. Besides, fuel prices, consumer characteristics, accessibility of charging stations, and public visibility or social norms are among the external factors of user acceptance that affect EVs adoption. According to the study, the stakeholders need to understand each factor's value and how it can impact the adoption process to develop effective strategies to address each factor.

Thru this study, articles produced throughout the databases were collected and reviewed to discuss how these elements can be tackle before the mass adoption of EVs in a supportive environment. The conceptional model of EVs produced by this study is shown in Figure 1

Technology Readines

Infrastructure Readiness

City
Readiness
factors

Figure 1: Conceptual model of electric vehicle

\section{CONCLUSION}

As conclusion, five categories of EVs readiness shown in Figure 1. The variables include the readiness for technology, infrastructure, advertising and promotion, government support, and consumer acceptance. The adoption process is complex based on this study and includes various vital factors that need detailed consideration before the execution phase can start. Moreover, the readiness categories identified from the critical literature review process, despite all the difficulties, are essential to help practitioners and execution teams identify the key areas that need critical attention. All stakeholders need to play their role in addressing these factors in making EVs' adoption come true to implement EVs successfully.

\section{REFERENCES}

[1] Alawadhi, M., Almazrouie, J., Kamil, M., \& Khalil, K. A. (2020). A systematic literature review of the factors influencing the adoption of autonomous driving. International Journal of Systems Assurance Engineering and Management. https://doi.org/10.1007/s13198-020-00961-4

[2] Bansal, P., Kockelman, K. M., \& Singh, A. (2016). Assessing public opinions of and interest in new vehicle technologies: An Austin perspective. Transportation Research Part C, 67, 1-14.

[3] Baraba's I, Todorut, A, Cordos, N, Molea A (2017) Current challenges in autonomous driving. In: 
IOP conference series: materials science and engineering, vol 252, no. 1. IOP Publishing, p 012096

[4] Brown, A. (2016, March 16). Tech Insider. Retrieved January 31, 2017, from Here's the story behind GM's revolutionary electric car from the 90s that disappeared: http://www.businessinsider.com/gm-ev1history-2016-3 ?r=US\&IR=T\&IR=T/\#there-was- a-tonof-excitement-when-the-ev1-was-first-released-in-late1996-1

[5] Carley, S., Krause, R., Lane, B., \& Graham, J. (2013). Intent to purchase a plug-in electric vehicle: A survey of early impressions in large US cities. Transportation Research Part D, 18, 39-45.

[6] Coffman, M., Bernstein, P., \& Wee, S. (2017). Electric vehicles revisited: a review of factors that affect adoption. Transport Reviews, 37(1), 79-93. https://doi.org/10.1080/01441647.2016.1217282

[7] Cook DJ, Mulrow CD, Haynes RB (1997) Systematic reviews: synthesis of best evidence for clinical decisions. Ann Intern Med126(5):376-380

[8] Curtis D. Anderson, J. A. (2010). Electric and Hybrid Cars: A History. McFarland; 2 edition.

[9] Dimitropoulos, A., Rietveld, P., \& Ommeren, J. (2013). Consumer valuation of changes in driving range: A meta-analysis. Transportation Research Part A, $55,27-45$.

[10] Dobni, C. B. (2008). Measuring innovation culture in organizations. European Journal of Innovation Management, 11(4), 539-559.

[11] EPA, (2017, Jan 19). Fast Facts on Transportation Greenhouse Gas Emissions. United State Environmental Protect Agency. Retrieved from https://www.epa.gov/greenvehicles/fast-factstransportation-greenhouse-gas-emissions

[12] Funke, S. A., Jochem, P., Ried, S., Gnann, T., 2019. Fast charging stations with stationary batteries - a techno-economic comparison of fast charging at highways and in cities. World Conference on Transport Research - WCTR 2019 Mumbai 26-31 May 2019.

[13] Hackbarth, A., \&Madlener, R. (2013). Consumer preferences for alternative fuel vehicles: A discretechoice analysis. Transportation Research Part D, $25,5-17$.

[14] Hardman S., et al.A review of consumer preferences of and interactions with electric vehicle charging infrastructure Transp. Res. Part D: Transp. Environ. (2018), 10.1016/j.trd.2018.04.002

[15] Hauksson G. (2011). Quantitative analysis of the potential of electric vehicle utilization: methodology design and preliminary study.Hidrue, M., Parsons, G., Kempton, W., \& Gardner, M. (2011). Willingness to pay for electric vehicles and their attributes. Resource and Energy Economics, 33, 686-705.

[16] IEA (2016), CO2 Emissions from Fuel Combustion 2016, OECD Publishing Paris, https://doi.org/10.1787/co2_fuel-2016-en.

[17] Kanter, R. M. (1988). When a thousand flowers bloom: Structural, collective, and social conditions for innovation in organization. Research in Organizational Behavior, eds.Staw BM and Cummings LL, 10, 169211.

[18] Lee, C. T., Hashim, H., Ho, C. S., Fan, Y. Van, \& Klemeš, J. J. (2017). Sustaining the low-carbon emission development in Asia and beyond: Sustainable energy, water, transportation and low-carbon emission technology. Journal of Cleaner Production, 146, 1-13. https://doi.org/10.1016/j.jclepro.2016.11.144

[19] Li, W., Long, R., Chen, H., \& Geng, J. (2017). A review of factors influencing consumer intentions to adopt battery electric vehicles. Renewable and Sustainable Energy Reviews, 78(December 2016), 318328. https://doi.org/10.1016/j.rser.2017.04.076

[20] Lie, T. T., Prasad, K., \& Ding, N. (2017). The electric vehicle: a review. International Journal of Electric and Hybrid Vehicles, 9(1), 49. https://doi.org/10.1504/ijehv.2017.10003709

[21] Leitman, S., \& Brant, B. (2009). Build your own Electric Vehicle (2nd Edition ed.). New York, United State.Matulka, Rebecca(2000), Timeline: History of the Electric Car. Retieve fromhttps://energy.gov/articles/history-electric-car. U.S. Department of Energy

[22] Lutsey, N. (2017). Integrating electric vehicles within $\mathrm{U} . \mathrm{S}$. and European efficiency regulations. INTERNATIONAL COUNCIL ON CLEAN TRANSPORTATION, 6(June), 3-8.

[23] Matulka, Rebecca(2000), Timeline: History of the Electric Car. Retieve from https://energy.gov/articles/history-electric-car. U.S. Department of Energy

[24] Mosaberpanah, M. A., \& Khales, S. D. (2013). The role of transportation in sustainable development. ICSDEC 2012: Developing the Frontier of Sustainable Design, Engineering, and Construction - Proceedings of the 2012 International Conference on Sustainable Design and Construction, February 2018, 441-448. https://doi.org/10.1061/9780784412688.053

[25] Nikitas A, Njoya ET, Dani S (2019) Examining the myths of connected and autonomous vehicles: analysing the pathway to adriverless mobility paradigm. Int J AutomotTechnol Manage 19(1-2):10-30 
[26] Oliveira CMD, De Mello A, Bandeira R, Vasconcelos Goes G, Schmitz Gonçalves DN, D'Agosto MDA (2017) Sustainable vehicles-based alternatives in last mile distribution of urban freight transport: A systematic literature review. Sustainability $9(8): 1324$

[27] Palinski, M. (2017). A Comparison of Electric Vehicles and Conventional Automobiles: Costs and Quality Perspective.

[28] Pelletier, S., Jabali, O., \& Laporte, G. (2014). Battery Electric Vehicles for Goods Distribution: A Survey of Vehicle Technology, Market Penetration, Incentives and Practices. Cirrelt, September, 51.

[29] Ramayah, T., Lee, J. W. C., \& Mohamad, O. (2010). Green product purchase intention: Some insights from a developing country. Resources, Conservation and Recycling, 54(12), 1419-1427. https://doi.org/10.1016/j.resconrec.2010.06.007

[30] Seth Leitman, B. B. (2009). Build your own electric vehicle (2nd ed.). McGraw-Hill.

[31] Sierzchula, W., Bakker, S., Maat, K., \& Wee, B. (2014). The influence of financial incentives and other socio-economic factors on electric vehicle adoption. Energy Policy, 68, 183-194.

[32] Thome' AMT, Scavarda LF, Scavarda AJ (2016) Conducting systematic literature review in operations management. Prod Plan Control 27(5):408420

[33] Thompson, C. (2015, December 17). Tech Insider. Retrieved January 31, 2017, from The fascinating evolution of the electric car: http://www.businessinsider.com/electric- automobilehistory-2015-12?r=US\&IR=T\&IR=T/\#the-electric-carsfirst-heyday-was-in- the-late-1800s-and-early-1900s-1

[34] Tranfield D, Denyer D, Smart P (2003) Towards a methodology for developing evidenceinformed management knowledge by means of systematic review. Br J Manag 14(3):207-222

[35] Tushman, M. L., \& O Reilly, C. A., III. (1996). Ambidextrous organizations: Managing evolutionary and revolutionary change. California Management Review, 38(4), 8-30.

[36] Wang, N., \& Liu, Y. (2015). City Readiness System Assessment of Electric Vehicle Adoption in China. SAE International Journal of Materials and Manufacturing. https://doi.org/10.4271/2015-01-0469

[37] Will, C., \& Schuller, A. (2016). Understanding user acceptance factors of electric vehicle smart charging. Transportation Research Part C: Emerging Technologies, 71, 198-214. https://doi.org/10.1016/j.trc.2016.07.006 